\title{
Radiation exposure from diagnostic procedures in patients with newly diagnosed breast cancer
}

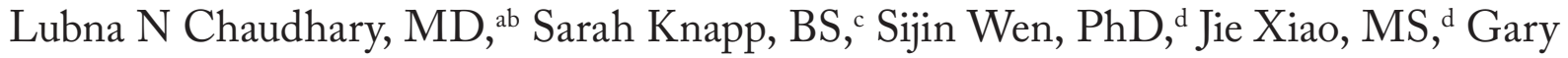 \\ Marano, MD, ${ }^{\mathrm{e}}$ Sobha Kurian, MD ${ }^{2}$ Ginger Layne, MD, ${ }^{\mathrm{e}}$ Geraldine Jacobson, $\mathrm{MD},{ }^{\mathrm{e}}$ and \\ Jame Abraham, MD, FACP ${ }^{\text {bf }}$
}

${ }^{\mathrm{a}}$ Division of Hematology and Oncology, Froedtert and Medical College of Wisconsin, Milwaukee; ${ }^{\mathrm{b}}$ Section of Hematology and Oncology, Departments of ${ }^{\mathrm{c} M e d i c i n e,}{ }^{\mathrm{d} B i o s t a t i s t i c s,}$ and ${ }^{\mathrm{e}}$ Diagnostic Radiology and Nuclear Medicine, West Virginia University, Morgantown; and ${ }^{\mathrm{f} D e p a r t m e n t}$ of Solid Tumor Oncology, Cleveland Clinic, Cleveland, Ohio

Radiation exposure is associated with an increased risk of secondary cancers. Knowing the approximate radiation exposure from diagnostic procedures in the first year after a breast cancer diagnosis could help educate patients and allow physicians to monitor them more closely for potential risks.

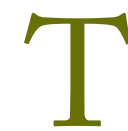

The use of diagnostic imaging and radiationbased therapies has increased rapidly over the past decade, particularly in oncology. ${ }^{1}$ Increased exposure to medical radiation has raised concerns about health risks and in particular, an increased risk of secondary cancers. ${ }^{2}$ The probability of occurrence of the chronic effects of ionizing radiation is a function of the total radiation dose. ${ }^{3,4}$ There are limited data on radiation exposure from diagnostic procedures (DPs) in breast cancer patients. Although patients who have been diagnosed with breast cancer undergo radiation-based diagnostic and staging work-up that is deemed medically necessary, there remains a growing concern about the possible long-term side effects of radiation exposure. Breast cancer is the most common cancer among women worldwide, and the number of breast cancer survivors has increased notably in the past decade. In the United States, as of 2012, nearly 3 million women have a history of breast cancer and constitute more than $40 \%$ of female cancer survivors. ${ }^{4}$ The objective of our study was to quantify the radiation dose experienced by breast cancer patients during the first year of their diagnosis. Patients with earlystage breast cancer have a good overall prognosis and survival, hence it is important to be vigilant about possible long-term side effects associated with radiation exposure in such patients. There are currently no additional screening guidelines for cancer survi- vors to detect secondary cancers, however knowing the approximate radiation exposure and associated potential risks could help educate patients and allow physicians to monitor them more closely.

\section{Methods}

We performed a retrospective chart review study to analyze the cumulative radiation doses (millisievert $[\mathrm{mSv}]$ ) of routine DPs performed during the first year after breast cancer diagnosis. In all, 305 patients with newly diagnosed breast cancer who were treated at West Virginia University during January 2008-October 2010 were included in our study. Data regarding the frequency of DP including mammograms, sentinel lymph node biopsies, $\mathrm{X}$-rays, computed-tomographic (CT) and/or positron emission tomographic (PET) scans, MUGA scans and bone scans were collected. Mean radiation doses of the DPs were obtained from the departments of nuclear medicine and radiation at our institution (Table 1). We used Kruskal-Wallis test and post hoc pairwise comparisons to assess the influence of age, histology, estrogen/progesterone receptor (ER/PR) status, and disease stage on the amount of radiation exposure. We also performed a subgroup analysis to evaluate the effect of those factors on the number of positron emission tomography-computed tomography (PET-CT) scans. All statistical tests with 2-sided $P<.05$ were considered statistically significant.

Accepted for publication January 13, 2014. Correspondence: Lubna N Chaudhary, MD; Ichaudhary@mcw.edu. Disclosures: The authors have no disclosures. JCSO 2015;13:27-29. @2015 Frontline Medical Communications. DOI 10.12788/jicso.0103. 


\section{Results}

Most of our patients were aged 40-60 years $(n=162)$ and most had infiltrating ductal carcinoma (IDC; $\mathrm{n}=198$; Table 2). Patients who were younger than 40 years received

\begin{tabular}{|lc|}
\hline $\begin{array}{l}\text { TABLE } 1 \text { Radiation doses from various diagnostic procedures } \\
\text { Procedure }\end{array}$ & Mean dose, mSV \\
\hline Mammogram (bilateral) & 0.4 \\
\hline Stereotactic biopsy & 0.2 \\
Sentinel LN biopsy & 0.4 \\
Chest X-ray & 0.1 \\
PET-CT & 24 \\
MUGA scan & 9.4 \\
CT & \\
Brain & 2.0 \\
Neck & 6.0 \\
Chest & 7.0 \\
Chest/abd/pelvis & 18.0 \\
Abd/pelvis & 10.0 \\
Pelvis & 6.0 \\
\hline Bone scan & 6.3 \\
\hline Abd, abdomen; CT, computed tomography; LN, lymph node; MUGA, mul- \\
tigated acquisition scan; PET-CT, positron emission tomography-computed \\
tomography \\
\hline
\end{tabular}

TABLE 2 Mean and median of the total radiation doses by groups

\begin{tabular}{|c|c|c|c|c|}
\hline \multirow[b]{2}{*}{ Group } & \multirow{2}{*}{$\begin{array}{l}\text { No. of } \\
\text { patients }\end{array}$} & \multicolumn{2}{|c|}{ Radiation dose, mSV } & \multirow[b]{2}{*}{$\boldsymbol{P}$} \\
\hline & & Mean (SE) & Median (IQR) & \\
\hline Overall & 305 & $21.94(1.51)$ & $7.80(32.10)$ & - \\
\hline Age, y & & & & .0187 \\
\hline $\begin{array}{l}<40 \\
40-60 \\
>60\end{array}$ & $\begin{array}{l}19 \\
162 \\
123\end{array}$ & $\begin{array}{l}35.94(8.65) \\
22.53(2.00) \\
19.18(2.27)\end{array}$ & $\begin{array}{c}25.10(25.50) \\
10.30(33.60) \\
6.80(28.90)\end{array}$ & $\begin{array}{l}- \\
- \\
-\end{array}$ \\
\hline Histology & & & & $<.0001$ \\
\hline $\begin{array}{l}\text { DCIS } \\
\text { IDC } \\
\text { ILC } \\
\text { Others }\end{array}$ & $\begin{array}{c}60 \\
198 \\
26 \\
13\end{array}$ & $\begin{array}{c}8.54(2.19) \\
26.69(2.04) \\
22.38(3.43) \\
20.28(6.52)\end{array}$ & $\begin{array}{c}2.10(5.15) \\
24.90(35.60) \\
25.40(24.00) \\
19.00(23.80)\end{array}$ & $\begin{array}{l}- \\
- \\
- \\
-\end{array}$ \\
\hline$E R / P R$ & & & & .0052 \\
\hline $\begin{array}{l}\text { Negative } \\
\text { Positive }\end{array}$ & $\begin{array}{c}54 \\
224\end{array}$ & $\begin{array}{l}31.79(4.08) \\
21.10(1.69)\end{array}$ & $\begin{array}{c}26.35(32.90) \\
7.30(32.25)\end{array}$ & - \\
\hline Stage & & & & $<.0001$ \\
\hline $\begin{array}{l}0 \\
\text { I } \\
\|/\| A \\
\text { IIB } \\
\text { III/A-C } \\
\text { IV }\end{array}$ & $\begin{array}{l}18 \\
105 \\
48 \\
25 \\
35 \\
12\end{array}$ & $\begin{array}{l}7.62(4.60) \\
13.28(1.79) \\
24.73(3.57) \\
36.03(3.09) \\
42.04(4.88) \\
76.68(7.92)\end{array}$ & $\begin{array}{c}2.25(4.30) \\
5.80(22.90) \\
25.25(29.75) \\
34.40(14.30) \\
35.60(24.90) \\
72.80(27.30)\end{array}$ & $\begin{array}{l}- \\
- \\
- \\
- \\
- \\
-\end{array}$ \\
\hline
\end{tabular}

DCIS, ductal carcinoma in situ; ER/PR, estrogen/progesterone receptor; IDC, infiltrating ductal carcinoma; ILC, invasive lobular carcinoma; IQR, interquartile range a significantly higher radiation dose compared with those who were older than 60 years $(35.9 \mathrm{mSv}$ and $19.2 \mathrm{mSv}$, respectively; $P=.009$ ). Patients with ductal carcinoma in situ (DCIS) had significantly less exposure to radiation than did patients with IDC and invasive lobular carcinoma (ILC): $8.5 \mathrm{mSv}, 26.7 \mathrm{mSv}$, and $22.4 \mathrm{mSv}$, respectively; $P<.0001$. Disease stage IIB or higher was associated with a significantly higher radiation exposure $(P<.0001)$. Disease stage IIIA or higher was the only factor associated with a higher radiation dose from PET-CTs $(P<.0001)$. The mean radiation exposure relative to various factors is shown in Table 2.

\section{Conclusion}

Most of the evidence on radiation-induced health risks is based on data from survivors of the Hiroshima and Nagasaki atomic bomb blasts. ${ }^{5}$ These data provide compelling evidence of radiation-induced cancer risk at doses higher than $100 \mathrm{mSV} .^{3}$ Radiation-induced risk is more controversial at doses between 10 and $100 \mathrm{mSV}$ because estimating the risk of developing cancer from an individual radiologic study is not clear, given the stochastic nature of harm from ionizing radiation and the limited epidemiologic data. However, there is mounting consensus in the medical and scientific communities that the risk to the patient is real, however small.

The 2006 Biological Effects of Ionizing Radiation (BEIR VII-Phase 2) risk model on lifetime attributable cancer predicts that 1 in 1,000 persons exposed to 10 $\mathrm{mSV}$ will develop cancer because of that singleexposure. ${ }^{3}$ The International Commission on Radiological Protection has confirmed that doses for diagnostic exams such as CT scans approach or exceed levels associated with an increase in lifetime cancer risk. ${ }^{6}$

Our study has attempted to quantify the radiation doses associated with diagnostic procedures in breast cancer patients. Although our patients underwent diagnostic procedures and imaging for necessary diagnosis and management of breast cancer, given the high overall survivorship in breast cancer patients, it is imperative to educate both patients and physicians about the possible long-term health risks associated with radiation exposure, including the development of secondary cancers. There are no current recommendations to offer additional screenings to cancer survivors except the general age-appropriate screenings, however knowing the approximate radiation dose experienced by these patients and potential risks associate with it will help patients and physicians monitor closely with details history and physical examinations.

The findings from our study show that radiation exposure from DPs is significant in the first year after a diagnosis of breast cancer, especially for younger patients and those with advanced stage disease, even though the potential risk 
associated with it is small. As far as we know, this is the first attempt to quantify the radiation exposure with DPs. Although we did not find any adverse event directly related to radiation exposure in our group of patients, given the short follow-up and retrospective nature of our study, we need to continue to scrutinize the effects of radiation exposure from DPs. Prospective studies with a longer follow-up are warranted to answer this important health concern.

\section{Acknowledgment}

This paper was originally presented as a poster at the ASCO Breast Cancer Symposium in San Francisco in September 2013.

\section{References}

1. Mettler FA Jr, Bhargavan M, Faulkner K, et al. Radiologic and nuclear medicine studies in the United States and worldwide: frequency, radiation dose, and comparison with other radiation sources - 1950-2007. Radiology. 2009;253:520-531.

2. Brenner DJ, Hall EJ. Computed tomography - an increasing source of radiation exposure. N Eng1 J Med. 2007;357:2277-2284.

3. National Academy of Sciences/National Research Council. Health risks from exposure to low levels of ionizing radiation, BEIR VII, Phase 2. National Academy Press, Washington DC; 2006.

4. [No authors listed.] Radiation and your patient: A guide for medical practitioners. Ann ICRP. 2001;31:5-31.

5. Pierce DA, Preston DL. Radiation-related cancer risks at low doses among atomic bomb survivors. Radiat Res. 2000;154:178-186.

6. Task group on control of radiation dose in computed tomography. Managing patient dose in computed tomography. A report of the international commission on radiological protection. Ann ICRP. 2000;30:7-45. 